\title{
Effect of Role Models - A Critical Study on the Recent Research Contribution of Vice-chancellors of Selected Private Universities in India
}

\author{
P. S. Aithal \\ Srinivas Institute of Management Studies, Srinivas University, Mangalore - 575 001, INDIA. \\ E-mail: psaithal@gmail.com
}

\begin{abstract}
Many Countries around the globe have adopted private University system as a part of their higher education offering strategy. India, being the second highest in the number of private universities in the World, has given exactly $50 \%$ shares to privately governed Universities (Private \& Deemed to be universities together) and remaining 50\% are Govt. Funded universities (Central \& State Govt. together). Presently in India, there are 264 private universities spread over 22 states. Along with providing latest industry-oriented higher education training and placement, private universities are also have the challenge to involve both students and faculties in innovative research in order to increase the research output. While discussing the challenges of increasing the research productivity in organizations, recently proposed Theory of Accountability (Theory A) suggests the strategy of showing 'Role models' in the organizations to the researchers so that the target of each and every researcher can be substantially increased with the slogan - 'It is Possible'. In this paper, we have proposed the responsibility of Vice-chancellors as Role models for researchers to boost the research output of the universities by adding self-contribution of them in the form of research publications. In this regard, we have studied the contribution of Vicechancellors to present them as Role models to researchers in private universities due to their less administrative responsibilities compared to public university Vice-chancellors in India. The research contributions in the form of published papers in journals for the last 5 years is tabulated, analysed, and discussed to see the Role model characteristics and is compared with an optimistic estimate, realistic estimate, and pessimistic estimate of our theoretical prediction. Finally, the reasons for the negative result and some guidelines are suggested to increase the Vice-chancellors contribution to increase the research productivity along with the brand image of the universities.
\end{abstract}

Keywords: Research contribution, Research performance, Vice-chancellor, Private universities, Role model, Leader.

\section{How to Cite this Paper:}

Aithal, P. S. (2018). Effect of Role Models - A Critical Study on the Recent Research Contribution of Vice-chancellors of Selected Private Universities in India. International Journal of Management, Technology, and Social Sciences (IJMTS),3(1), 118-139. DOI : http://doi.org/10.5281/zenodo.1257729. 